\title{
A IMPRENSA PERIÓDICA COMO FONTE PARA A HISTÓRIA DA EDUCAÇÃO: TEORIA E MÉTODO
}

\author{
Cézar de Alencar Arnaut de Toledo ${ }^{1}$ \\ Universidade Estadual de Maringá \\ caatoledo@uem.br \\ Oriomar Skalinski Junior ${ }^{2}$ \\ Universidade Estadual de Maringá \\ jrskalinski@yahoo.com.br
}

\section{RESUMO}

Este artigo tem como objetivo discutir teorias, métodos e técnicas empregadas no tratamento de fontes nas pesquisas em História da Educação, e, especialmente, as particularidades metodológicas na utilização da imprensa periódica como fonte. As discussões relativas ao tratamento, ao uso, bem como às modalidades de fontes ganharam importância entre os historiadores da educação no Brasil, notadamente, a partir da década de 1980. As fontes são produções humanas, portanto, nas suas mais diversas modalidades, são registros das relações entre os homens em um dado momento histórico. Neste sentido, ao fazerem circular informações sobre questões relativas à educação de modo amplo, bem como sobre as particularidades do trabalho pedagógico, os periódicos, independentemente de serem especializados nestas questões, são uma rica fonte de informações para pesquisas em História da Educação.

Palavras-chave: História da Educação; fontes; imprensa periódica.

\section{PERIODICAL PRESS AS A SOURCE FOR THE HISTORY OF EDUCATION: THEORY AND METHODS}

\begin{abstract}
This article aims to discuss theories, methods and techniques used in the treatment of sources in the history of education research, and especially the methodological peculiarities in the use of the periodical press as a source. Discussions on the processing, use, and the modalities of sources gained importance among historians of education in Brazil, especially from the $1980 \mathrm{~s}$. The sources are human productions, therefore, in its various forms, are records of relations between men in a given historical moment. In this sense, by making information circulate on issues related to education broadly, as well as on the particularities of pedagogical work, the periodical press, specialized or not in these issues, are a rich source of information for research in History of Education.
\end{abstract}

Keywords: History of Education; sources; periodical press.

\section{Considerações iniciais}

O presente trabalho tem o objetivo de discutir teorias, métodos e técnicas empregadas no tratamento de fontes nas pesquisas em História da Educação, e, especialmente, as particularidades metodológicas na utilização da imprensa periódica como fonte. Os avanços tecnológicos trouxeram algumas facilidades para pesquisas no campo da história, particularmente, as proporcionadas pela digitalização de fontes e sua 
disponibilização em redes eletrônicas. $\mathrm{O}$ acesso às versões digitais de diferentes modalidades de fontes, especialmente às mais antigas, tornou-se um instrumento valioso que serve aos pesquisadores - das diferentes áreas que realizam pesquisas históricas - na medida em que pode eliminar muitos entraves de ordem prática. A possibilidade de acessar fontes sem a necessidade de grandes deslocamentos traz, obviamente, uma nova dinâmica para as pesquisas. É necessário, entretanto, que os historiadores das diferentes áreas, antes do contato direto com suas fontes, dediquem-se, em sua formação e/ou preparação específica, à pesquisa e à aquisição das ferramentas metodológicas que farão a mediação entre eles e suas fontes.

Este texto divide-se em três partes. Na primeira, intitulada "História da Educação no Brasil", são debatidos alguns elementos relativos à história do campo, com o foco em sua constituição e modificações mais relevantes. Já na segunda parte, nomeada "Teoria, método e técnica no tratamento das fontes", discute-se, sob diversos aspectos, a utilização de fontes em pesquisas históricas. Consideram-se, especialmente, sobre as fontes: o significado, a modalidade, o emprego, métodos e técnicas para seu uso apropriado em pesquisas. Na última parte do texto, "Especificidades teórico-metodológicas: a imprensa periódica como fonte para pesquisas em História da Educação", focalizam-se as particularidades a serem observadas pelo historiador da educação no que tange o uso de jornais e revistas, sejam especializados em questões educativas ou não, como fonte para sua pesquisa. Destacam-se pontos como: o estatuto do conteúdo publicado, o papel social assumido pelo periódico, a materialidade do jornal ou revista, bem como as características distintivas da imprensa pedagógica.

\section{História da Educação no Brasil}

A História da Educação surgiu como uma especialidade da História no final do século XIX, entretanto, desenvolveu-se como campo disciplinar de modo mais próximo à Educação/Pedagogia. Marcadamente no Brasil, houve a aproximação entre História da Educação e Filosofia da Educação, e os conteúdos ministrados, ao menos até meados do século XX, tinham mais o objetivo de justificar a tarefa educativa e de explicitar as finalidades da educação do que propriamente um caráter investigativo ${ }^{3}$. Esta característica teria implicado em que a consulta a arquivos e a busca metódica por fontes, como prática para a escrita da história da educação, não tenha se constituído como atividade tradicional em nosso país (VIDAL; FARIA FILHO, 2003; SAVIANI, 2003).

Apesar da História da Educação ter principiado no Brasil como uma espécie de ciência auxiliar da pedagogia, trata-se de uma disciplina acadêmica com estatuto e objeto de estudo próprios. Neste sentido, na década de 1950 a História da Educação brasileira começou, efetivamente, a conquistar sua autonomia em relação à Filosofia da Educação e a apresentar características e metodologia próprias. Também os primeiros passos no que diz respeito à profissionalização de seus pesquisadores, principalmente como professores universitários, aconteceram de modo mais firme. Criadas estas condições, surgiram na década de 1960 os primeiros programas de Pós-Graduação, com as linhas de pesquisa relativas à História da Educação se tornando o local privilegiado para o debate e para as investigações (MONARCHA, 1996; VIDAL; FARIA FILHO, 2003).

Talvez até como um movimento de compensação pela não existência de uma tradição da prática de consulta a arquivos, especialmente, a partir da década de 1980 a 
busca por fontes se tornou discussão de primeira ordem entre os historiadores da educação. A constituição do GT de História da Educação na ANPEd em 1984 e do HISTEDBR na Unicamp em 1986, ilustram com propriedade esta preocupação, bem como o fortalecimento do campo (VIDAL; FARIA FILHO, 2003; SAVIANI, 2006) ${ }^{4}$.

A catalogação de fontes primárias e secundárias e a paralela expansão dos cursos de Pós-Graduação - com temáticas atinentes à História da Educação - na década de 1990, contribuíram para uma melhor definição da identidade da disciplina (SAVIANI, 2000). Com esta consolidação houve um impulso geral nas pesquisas, com avanços marcantes no campo de estudo, seja por meio de novos temas, que se estabeleceram como foco de interesse, seja pela retomada, muitas vezes sob novas perspectivas, de temas tradicionais.

\section{Teoria, método e técnica no tratamento das fontes}

Uma fonte pode ser entendida como o ponto de origem, a nascente a partir da qual uma necessidade é atendida. Para uma pesquisa histórica significa, fundamentalmente "[...] a base, o ponto de apoio, o repositório dos elementos que definem os fenômenos cujas características se busca compreender" (SAVIANI, 2006b, p. 28). A rigor a palavra fonte é empregada em história com sentido figurado, não se trata de considerar as fontes como a origem do fenômeno histórico, mas sim como algum tipo de registro ou testemunho de atos históricos (SAVIANI, 2006b). Pedro Paulo Funari indica que:

A noção mesma de fonte é originária do cientificismo que prevalecia no século XIX, preocupada que estava a História com a descoberta dos fatos verdadeiros. Fonte é uma metáfora, pois o sentido primeiro da palavra designa uma bica d'água, significado esse que é o mesmo nas línguas que originaram esse conceito, no francês, source, e no alemão, Quell. Todos se inspiraram no uso figurado do termo fons (fonte) em latim, da expressão "fonte de alguma coisa", no sentido de origem, mas com um significado novo. Assim como das fontes d'água, das documentais jorrariam informações a serem usadas pelo historiador (FUNARI, 2006, p.85).

No que tange às pesquisas históricas, obviamente, não é razoável falar em fontes naturais. Por sua própria definição, fontes históricas são produções humanas das mais diversas modalidades. Podem ser documentos, vestígios, indícios, produzidos com o propósito de registro ou não, que se acumularam ou foram guardados e que adquirem o estatuto de fonte mediante a intencionalidade do historiador, que traz consigo o problema de sua pesquisa. Nas fontes são buscadas respostas às questões levantadas (SAVIANI, 2006b).

Tradicionalmente as fontes são classificadas como primárias ou secundárias. Fontes primárias são aquelas que guardam relação direta com o tema e/ou com o problema da pesquisa. Podem ser, por exemplo, produções do autor estudado, cartas, diários, documentos do período pesquisado e ligados à temática da pesquisa. São as fontes mais próximas à origem - portanto, originais - das informações que o pesquisador se empenha em conseguir. Já as fontes secundárias são aquelas que possibilitam a apreensão dos fatos concernentes ao tema estudado de modo indireto. São relatos feitos por pessoas que, baseadas em fontes orais ou documentais, vivenciaram diretamente o que é relatado. A característica descrita não desmerece esta modalidade de fonte. As fontes secundárias podem trazer informações valiosas para a pesquisa, especialmente, pelo fato de possibilitarem constituição de um lastro de informações. Em geral proporcionam uma melhor compreensão de datas e fatos, de conceitos e representações pertinentes ao período 
estudado, auxiliam na configuração do referencial teórico-metodológico, bem como podem significar o necessário contraponto às fontes primárias (ARNAUT DE TOLEDO; GIMENEZ, 2009). Nestes termos, uma fonte por si mesma não é primária nem secundária. São os propósitos e a maneira como será utilizada na pesquisa que determinarão sua classificação.

Embora as pesquisas históricas possam ser realizadas em diferentes áreas, o ofício investigativo do historiador possui procedimentos que são generalizáveis. Uma investigação de caráter histórico se sustenta nas informações obtidas em fontes, com os pesquisadores apropriando-se das informações por meio de métodos e técnicas que se articulem à sua abordagem teórica (PINSKY, 2006). Uma pesquisa histórica que não lance mão de fontes primárias, possivelmente, encontrará resistências na comunidade acadêmica. A demanda pela utilização de fontes primárias traz consigo preocupações acerca do uso e da qualificação das peças documentais. "As fontes não "falam" por si só, não adquirem sentido por elas mesmas, daí a necessidade do diálogo científico com os documentos, diálogo que passa, muitas vezes, por uma relação de saudável desconfiança" (COSTA, 2010, p. 193).

Para a construção de uma pesquisa histórica bem alicerçada um dos passos fundamentais é, ainda na fase de planejamento, a seleção criteriosa de fontes. Este momento é vital para o pesquisador, pois o conjunto de fontes será o manancial de sua interpretação. Nestes termos, uma seleção aligeirada e pouco judiciosa pode significar o malogro da pesquisa, em razão, por exemplo, do material não oferecer de fato os elementos necessários para que se alcancem os objetivos. Eventualmente, pode ser possível uma correção de rumo, mas, no mínimo este mau passo terá significado perda de tempo, de energia e de recursos. Daí a exigência de que o pesquisador tenha clareza dos critérios que orientarão sua seleção. Uma revisão minuciosa daquilo que já foi publicado sobre o tema e o domínio do repertório de categorias de análise da orientação teórica assumida, são marcos para a seleção de fontes que possam oferecer respostas ao problema da pesquisa. Não podem ser negligenciados pelo pesquisador, critérios como: pertinência, autenticidade, autoridade, credibilidade e acessibilidade (ARNAUT DE TOLEDO; GIMENEZ, 2009).

Pesquisadores menos experientes podem desenvolver uma verdadeira obsessão por fontes inéditas, acreditando que esta originalidade garantiria, por si só, novidades nos resultados revelando aspectos ainda não considerados sobre a temática estudada. Esta perspectiva negligencia a constante possibilidade de se visualizar novos aspectos mesmo de fontes já conhecidas (COSTA, 2010). Isto fica manifesto, especialmente, quando se tem em vista que:

[...] embora a história, o fato, esteja no passado, a apreciação do fato é sempre contemporânea ao historiador e tal "apreciação" decorre, em grande medida, da historicidade do pesquisador. Sendo assim, o surgimento de novas abordagens, a visualização de novos aspectos de uma determinada realidade, resulta muito mais das transformações no tempo presente e da forma de inserção do pesquisador em seu próprio mundo do que propriamente da incorporação de novas fontes (COSTA, 2010, p. 195).

Disto a necessidade de métodos e procedimentos claros e objetivos, que sirvam como um filtro entre o pesquisador e suas fontes. Este cuidado tem a finalidade de conter, ou, pelo menos reduzir, a "contaminação" das fontes pela subjetividade do pesquisador. Obviamente, a interpretação que o investigador fará de suas fontes será balizada pelas demandas históricas de sua própria circunstância, afinal de contas, há uma intencionalidade 
em sua pesquisa. Entretanto, o historiador não deve cobrar do passado, de modo anacrônico, respostas imediatas para os problemas emergentes para os quais esteja empenhado em dar respostas.

Cabe ao pesquisador o cuidado de examinar a fonte sem se submeter a ela, ou seja, sem tomá-la como peça portadora da verdade sobre os fatos históricos. Não existem documentos neutros. Desconfiar da fonte e das intenções de quem a produziu é um procedimento que, devidamente respaldado na contextualização e na história da peça documental, pode significar o primeiro passo para a construção de uma nova perspectiva (BACELAR, 2006; MELO 2010). Nestes termos, perguntas como "Sob quais condições aquele documento foi redigido? Com que propósito? Por quem?" (BACELAR, 2006, p. 63), são imprescindíveis para a condução de pesquisas documentais rigorosas.

Por múltiplas razões, uma fonte pode ser portadora de enganos, interpolações, falsificações, observações imprecisas de fatos, falta de habilidade e/ou negligência em sua exposição, alterações provocadas por interesses, ideologias e/ou paixão nas suas mais variadas manifestações [..] (MELO, 2010, p.18).

Os historiadores das diferentes áreas devem dar conta destas questões por meio de um "diálogo com as fontes", caso contrário suas pesquisas terão embaraços que, possivelmente, serão impeditivos para a construção do debate efetivamente acadêmico. São as precauções metodológicas que oferecem ao pesquisador as condições objetivas para "cotejar informações, justapor documentos, relacionar texto e contexto, estabelecer constantes, identificar mudanças e permanências e produzir um trabalho de História" (BACELAR, 2006, p. 71).

As pesquisas históricas tradicionalmente valorizaram as fontes escritas, com posição destacada, para o exame de documentos levantados em arquivos. Este fato é tributário da visão positivista de história, cujo foco está no conteúdo explícito dos documentos (ARNAUT DE TOLEDO; GIMENEZ, 2010). Foi em meados do século XX que esta concepção, que entendia um documento histórico como, necessariamente, uma peça escrita, manuscrita ou impressa começou a ser flexibilizada (MELO, 2010). O fortalecimento de proposições metodológicas diferentes da positivista implicou na valorização de outras modalidades de fontes. Carla Bassanezi Pinsky sinaliza uma questão interessante ao afirmar que os "documentos que "falavam" com os historiadores positivistas talvez hoje apenas murmurem, enquanto outros que dormiam silenciosos querem se fazer ouvir" (PINSKY, 2006, p. 7). Nestes termos, uma fonte histórica pode ser entendida como qualquer peça por meio da qual seja possível obter informações sobre o passado. Vale indicar que já na década de 1930 a Escola dos Annales, ao ampliar as fontes de pesquisa histórica para além das tradicionais, deu contribuições decisivas para a constituição da nova perspectiva sobre as modalidades e o uso das fontes (BURKE, 1992).

Quando se discute as pesquisas em História da Educação na atualidade, e mesmo nas Ciências Humanas em geral, imediatamente, é demarcada uma ampla compreensão do que seriam fontes pertinentes para uma pesquisa. $\mathrm{O}$ tempo em que apenas os documentos escritos e/ou antigos eram valorizados parece ter sido superado. Hoje são consideradas como fontes válidas para trabalhos em história elementos como: pinturas, filmes, fotografias, registros sonoros, arquitetura, traçado urbano, mobília, utensílios, entre outros itens pertencentes à materialidade cultural de uma época. Enfim, uma fonte se define acima de tudo pelos registros e/ou indícios nela objetivados. Até mesmo as fontes escritas/manuscritas tiveram ampliado seu rol de possibilidades, com as peças indicadas a seguir sendo frequentemente utilizadas como fonte documental: 
inscrições, correspondências, memórias, informes, regulamentos, planos, cartas funcionais, bulas, cedulários, [...] livros de textos, apontamentos, dicionários, estatísticas, textos pedagógicos, periódicos, revistas, guias, livros de conselhos, livros de atas, registro de matrícula, entre outros (MELO, 2010, p. 15).

Este amplo leque de fontes reposicionou as pesquisas históricas de modo geral e demandou do pesquisador das diferentes áreas que realizam esta modalidade de estudo, uma metodologia ainda mais acurada a fim de, efetivamente, cotejar diferentes modalidades de fontes, identificar os atores sociais envolvidos na objetivação das peças documentais e ainda relacionar as informações amealhadas com a totalidade das relações sociais. Estas necessidades implicaram na produção de métodos e técnicas específicos, a serem empregados de acordo com as características distintivas das fontes.

\section{Especificidades teórico-metodológicas: a imprensa periódica como fonte para pesquisas em história da educação}

As modificações da prática historiográfica ocorridas na segunda metade do século XX, de alguma maneira tributárias das proposições da Escola dos Annales, significaram uma ampliação do campo de estudo dos historiadores inclusive com a adoção de novos aportes analíticos como: a psicanálise, a linguística e a semiótica. Estas modificações não são concernentes apenas aos partidários da chamada História Nova, mas, também passou pela renovação da tradição marxista. Intelectuais como Raymond Williams, Perry Anderson, Eric Hobsbawm e Edward Thompson, articulados ao redor da New Left Review (1960), diferenciaram-se pela metodologia que, para além das questões referentes à economia política, ocupava-se dos elementos culturais entendendo-os como dotados de lógica específica (LUCA, 2006).

Estas modificações gerais implicaram em que estudos ligados à cultura, em seus pormenores, com trabalhos, por exemplo, sobre hábitos, costumes, gênero, minorias, ganhassem espaço na historiografia do final do século XX. Este movimento, comumente denominado de História Cultural, exalta os detalhes e os objetos modestos dedicando-se a particularidades (CASTANHO, 2010). Este contexto legitimou, sob muitos aspectos, a imprensa periódica como fonte primária para pesquisas históricas, entendendo-a não como um receptáculo de informação, mas como uma peça documental que traz em si um amplo espectro de elementos socioculturais do momento em que foi produzida (LUCA, 2006).

No Brasil o número de estudos históricos que se valiam da imprensa periódica como fonte, notadamente, jornais e revistas, eram escassos até a década de 1970. O que existia de significativo eram bibliografias sobre a difusão da imprensa no país, sobre a história de jornais e sobre o itinerário intelectual de jornalistas eminentes. Ou seja, havia uma produção consistente sobre História da Imprensa, entretanto, a ideia de se fazer História por meio da imprensa ainda encontrava muita resistência. Os jornais e revistas pareciam aos pesquisadores fontes pouco adequadas para trazer luz aos fatos históricos. A ideia corrente era a de que a imprensa, por ser resultado da convergência de interesses, compromissos e paixões, implicaria na composição de uma realidade distorcida. Um quadro parcial e subjetivo do cotidiano. Isto, a princípio, não satisfaria a critérios elementares como: objetividade, neutralidade, fidedignidade, credibilidade, e, talvez especialmente, o suficiente afastamento temporal dos fatos (LUCA, 2006).

Ao longo da década de 1970 a imprensa periódica, aos poucos, passou a ser considerada uma fonte válida. Este movimento significou no Brasil, concomitantemente, a apropriação e a sistematização de procedimentos e métodos a serem adotados para o 
tratamento adequado desta modalidade de fonte. Em dissertação de mestrado defendida na USP em 1974 e publicada em 1980, Maria Capelato tomou como objeto de estudo o jornal "O Estado de São Paulo". Este trabalho, intitulado "O Bravo Matutino", tornou-se modelar na historiografia brasileira, em razão de seu objeto, temática e abordagem. Neste texto, elaborado na primeira metade dos anos 1970, a autora já afirmava que a imprensa precisava ser entendida como:

[...] instrumento de manipulação de interesses e intervenção na vida social; nega-se, pois, aqui, aquelas perspectivas que a tomam como mero "veículo de informações", transmissor imparcial e neutro dos acontecimentos, nível isolado da realidade político-social na qual se insere (CAPELATO, 1980, p. 19)

É imperativo para aqueles que pretendem tomar a imprensa periódica como fonte em suas pesquisas, apropriar-se dos métodos, procedimentos e possibilidades analíticas que têm norteado as pesquisas. Muito de sua metodologia é generalizável para as diferentes áreas que realizam estudos históricos, portanto, as pesquisas em História da Educação partilham, de modo geral, das proposições básicas consagradas na academia no tratamento deste tipo de fonte.

O primeiro passo a ser dado pelo historiador, independentemente da especificidade de sua área de pesquisa, é o da classificação da modalidade de publicação. A diferenciação mais elementar na imprensa periódica é a feita entre jornais e revistas, entretanto, vale a observação de Luca (2006) quando indica que:

As definições hoje correntes, que reservam o termo jornal para a publicação diária em folhas separadas, e revista para as de periodicidade mais espaçada, enfeixadas por uma capa e com maior diversidade temática, tampouco esgotam a questão, pois sempre se pode citar os jornais semanais e seu afã de também tudo abarcar, ou as revistas extremamente especializadas. As classificações abstratas e generalizantes, por muito útil que sejam, não prescindem da caracterização específica construída a partir da análise do próprio corpo documental selecionado, as funções auto-atribuídas, em articulação constante com a sociedade, o tempo e o espaço no qual a fonte se insere (LUCA, 2006, p. 131-132).

Ou seja, a periodicidade, a apresentação física, bem como a estruturação e a especialização do conteúdo são critérios fundamentais para a definição da modalidade do periódico e devem ser empregados pelo historiador a fim de caracterizar sua fonte. Entretanto, vale o cuidado de se verificar se o simples emprego destas categorias conduzirá a uma classificação acertada, tendo em vista que, sob condições particulares, o sentido assumido pelo periódico no momento de sua circulação pode se sobrepor aos critérios indicados.

Outro ponto chave para o pesquisador é a clareza acerca do estatuto do conteúdo publicado na imprensa periódica. Trata-se de um tema difícil com questões referentes à objetividade do conteúdo, a sua neutralidade, e, especialmente, a possibilidade de se noticiar uma informação sem que isto implique, necessariamente, em uma interpretação. Neste sentido, a identificação dos atores sociais e das relações de interesse e ideológicas que permearam produção da fonte, bem como ferramentas provenientes da análise do discurso, auxiliam o pesquisador a problematizar o texto em questão. Em alguns periódicos, por exemplo, os objetivos comerciais em si mesmos podem ser secundários, 
com a função no segmento social que representava e/ou atingia sendo mais relevante. Um periódico que tinha o claro objetivo de defender uma perspectiva ou tomar parte em um debate, dando visibilidade a propostas e ideias, posiciona os textos que são objeto de análise de forma diferente quando comparados a textos de periódicos com fins estritamente comerciais. Discutindo os diversos tipos de imprensa, Antonio Gramsci ressalta que até em um mesmo segmento ideológico podem existir subdivisões marcantes (GRAMSCI, 2009). Com objetivo de ilustrar esta proposição mostra como a imprensa católica poderia ser subdividida em duas categorias: o "jornal católico em sentido lato" e o "jornal católico em sentido estrito".

Em sentido lato, o jornal 'católico' (ou sobretudo 'escrito por católicos') é o que não contém nada contra a doutrina e a moral católicas, e segue e defende suas normas. Dentro de tais linhas, o jornal pode defender orientações políticas, econômico-sociais ou científicas. Já o jornal 'católico' em sentido estrito é o que, de acordo com a autoridade eclesiástica, tem como finalidade direta um eficaz apostolado social cristão a serviço da Igreja e em apoio à Ação Católica (GRAMSCI, 2006, p. 198-199)

Nestes termos, Gramsci distingue um jornal de informação - ou sem partido, segundo sua terminologia - de um jornal de opinião - órgão oficial de uma organização, portanto, em sua terminologia, um jornal de partido. $\mathrm{O}$ primeiro majoritariamente destinado às massas e o segundo a um público necessariamente restrito. O exemplo da imprensa católica pode ser transposto para os demais segmentos sociais: liberais, comunistas, anarquistas, evangélicos, empresários, sindicatos de classe, enfim, qualquer segmento com características distintivas suficientemente solidificadas e demarcadas a ponto de identificá-lo como tal.

Para Gramsci (2006), na falta de partidos organizados e centralizados, os jornais agrupados em série acabam por desempenhar papel análogo ao de partidos políticos. Neste sentido, um periódico dificilmente é obra solitária. É, via de regra, um projeto coletivo que agrega pessoas ao redor de ideias, crenças, valores, interesses políticos, proveitos financeiros e propósitos de diferentes ordens. A assertiva de Gramsci faz ver a relevância da identificação, em uma pesquisa, do papel social desempenhado pelo periódico estudado. É imperativo identificar sua linha editorial, esmiuçar as ligações cotidianas de seus idealizadores e realizadores, rastrear os interesses financeiros e políticos que confluíram para a organização, para o lançamento e para a manutenção do periódico.

O pesquisador da imprensa periódica precisa ter a dimensão de que trabalha com aquilo que, por alguma razão, se tornou notícia. Portanto, deve considerar as motivações que levaram à decisão de se dar publicidade a alguma coisa, já que, certamente, muitos outros elementos que poderiam ser noticiados foram preteridos pelo periódico (LUCA, 2006). No limite, o historiador deve, inclusive, considerar em seu trabalho as temáticas ou fatos sobre os quais seu objeto de estudo silencia ou trata com negligência. O que demanda o conhecimento da economia política da época, da luta entre os atores sociais e de eventuais comprometimentos ideológicos assumidos pelo periódico. As fontes secundárias assumem um papel decisivo na constituição deste necessário contraponto à fonte primária.

Mais uma questão essencial é ponderar sobre o destaque dado a uma notícia. Uma notícia de capa a qual se dedicam muitas páginas na revista ou jornal, obviamente, precisa ser entendida e avaliada de modo diferente de uma notícia periférica e com pouco espaço nas páginas do periódico (LUCA, 2006). As razões que levaram um conteúdo a ter mais destaque do que outro, certamente devem ser consideradas pelo historiador, afinal, nem 
sempre estes motivos serão tão evidentes. Daí a necessidade de se ter clareza do papel social desempenhado pelo jornal ou revista. Distinguir se o periódico era ligado a algum grupo específico, se representava/expressava uma concepção política ou de mundo em particular, se propunha-se, ao menos em tese, a ser um veículo de comunicação neutro, todas estas são questões prementes para aquele que se propõe a pesquisar a história por meio de periódicos.

Outro elemento crucial a ser considerado: a seção do periódico em que o acontecimento é noticiado ou debatido. Existem hierarquias entre as seções e a alocação de uma notícia em um espaço ou em outro, pode, se devidamente analisada, proporcionar ao pesquisador informações sobre o periódico talvez até mais claras do que nos editoriais. Sobre este ponto Tânia Regina de Luca faz uma preciosa observação ao indicar que notícias relativas a movimentos sociais contemporâneos, sistematicamente são alocados pela imprensa hegemônica na "seção policial" em detrimento de outras seções que talvez fossem pertinentes como, por exemplo, "política nacional". Isto é exemplar para se entender a metáfora, comumente empregada no âmbito das pesquisas históricas: "deixar a fonte falar". Esta percepção por parte do pesquisador, talvez possa ser mais relevante para sua pesquisa do que a análise do conteúdo de muitos artigos. As informações na imprensa periódica, portanto, podem ser extraídas por diversos meios e cabe ao pesquisador a sensibilidade de inquirir suas fontes de maneira habilidosa. É a boa formação para a pesquisa que torna isto possível (LUCA, 2006).

Ainda um procedimento que não pode ser negligenciado pelo pesquisador é o de constituir uma série longa para análise. Ao selecionar um periódico para estudo, é importante que se tome um período suficientemente longo de publicação a ponto de garantir interpretações que não sejam apenas pontuais. Com isto, torna-se possível a constituição de unidades de análise generalizáveis, o que permite a apreensão de continuidades ou descontinuidades. Ou seja, as séries longas possibilitam que a pesquisa encontre o posicionamento majoritário do período estudado ou suas modificações. O que, ao menos a princípio, reduziria substancialmente o risco de se tomar o todo pela parte.

A materialidade do periódico também é um ponto relevante a ser considerado pelo pesquisador, pois traz informações decisivas acerca da peça que se pretende analisar. Um periódico, seja ele jornal ou revista, também veicula informações por meio de sua materialidade: tamanho, tipo de papel, qualidade de impressão, formato de suas folhas, uso de cores e imagens entre outros. Enfim, há uma ampla gama de elementos materiais que trazem consigo informações relevantes sobre a fonte. Portanto, o pesquisador que se propõe a adotar impressos periódicos como fonte primária, precisa considerar que $\mathrm{o}$ conteúdo e as ideias veiculadas por suas fontes não são os únicos elementos aos quais deve se dedicar. Um interessante exemplo é o do jornal mensal Correio Braziliense, que circulou de 1808 a 1822, e que possuía "o formato, mais próximo de um livro, com o número de páginas que podia chegar a 150, com extensão de artigos que se prolongavam por vários números [...]" (LUCA, 2006, p.131). Tratava-se de uma experiência de manuseio e de leitura, absolutamente diferente da que estamos acostumados nos jornais contemporâneos diários, ilustrados e coloridos. A experiência subjetiva do leitor ao travar contato com o periódico deve ser considerada no estudo, afinal de contas ela pode predispor o sujeito a uma experiência mais dura ou mais amigável com seu objeto de leitura. Assim, o uso de letras pequenas ou grandes, a organização em colunas ou em textos sem divisão, a encadernação, o tipo de papel, a capa, o uso de cores, a presença de fotos e figuras, o tamanho dos artigos/matérias, as características da linguagem utilizada, são elementos relevantes que contribuem, inclusive, para a caracterização do público à que o periódico se destinava. 
A adoção de uma apresentação mais sofisticada da publicação implicará em dois pontos chave para a imprensa: o preço do periódico e a seleção do público leitor. Em síntese: uma determinada materialidade implicará em determinado preço, que por sua vez implicará na seleção de determinado público leitor. Antonio Gramsci afirma que:

os leitores devem ser considerados de dois pontos de vista principais: 1) como elementos ideológicos, "transformáveis" filosoficamente, capazes, dúcteis, maleáveis à transformação; 2) como elementos "econômicos", capazes de adquirir as publicações e fazê-las adquirir por outros. Os dois elementos na realidade, nem sempre são separáveis, na medida em que o elemento ideológico é um estímulo ao ato econômico da aquisição e da divulgação. [...] Uma empresa editorial publica tipos diversos de revistas e livros, cuja gradação varia de acordo com os diversos níveis de cultura. [...] É observação generalizada a de que, num jornal moderno, o verdadeiro diretor é o diretor administrativo e não o diretor da redação (GRAMSCI, 2006, p. 246-247).

O pesquisador deve ser perguntar por que, dentro do que se dispunha no momento histórico em questão, aquelas características materiais foram escolhidas pelos editores do periódico. O fato de um jornal ou revista ter acabamento mais simples ou mais sofisticado, pode trazer, por exemplo, informações a respeito do perfil econômico do público ao qual se destinava, o que, por conseguinte, permite ao historiador a identificação da classe social alvo do periódico. Antonio Gramsci fala da existência de em um tipo de jornalismo integral que além de satisfazer as necessidades de seu público "[...] pretende também criar e desenvolver estas necessidades e, consequentemente, em certo sentido, gerar seu público e ampliar progressivamente sua área" (GRAMSCI, 2006, p. 197). Com isto em vista, é possível alcançar a modalidade de conteúdos destinados a uma classe social específica, bem como os posicionamentos, ao menos a princípio, compartilhados por uma média de leitores. Isto oferece à pesquisa informações relevantes acerca das preferências de diferentes ordens do público leitor. Esta manobra metodológica demonstra como técnica e condições materiais trazem por si só historicidade.

No que diz respeito à utilização da imprensa periódica em pesquisas em História da Educação, as possibilidades são amplas e o campo de estudo tem se mostrado fecundo e instigante. $\mathrm{O}$ contínuo crescimento do número de pesquisas nas últimas três décadas, notadamente, a partir de diferentes abordagens, indica que a adoção da imprensa como fonte não é prerrogativa de uma única perspectiva teórico-metodológica (SILVA; NASCIMENTO; ZICA, 2010). A possibilidade de se apreender pela via da imprensa as lutas sociais da época, e a compreensão de que a imprensa não apenas registrou os fatos, mas, inclusive, pode ter participado ativamente dos debates e das definições políticas, valoriza sobremaneira a fonte.

Os impressos representam significativos mananciais de informações sobre o repertório de uma época e sobre os usos que dele faziam seus colaboradores. Nele se fazem presentes projetos, opiniões, conflitos e debates, que apontam a complexidade dos interesses e experiências dos indivíduos e dos contextos em que se inscrevem (SILVA; NASCIMENTO; ZICA, 2010, p.223).

António Nóvoa ressalta a importância do estudo da imprensa especializada em educação, entendo-a como meio privilegiado para apreender a multiplicidade do campo. Enfatiza, especialmente, a potencialidade deste material sob três aspectos: 1. revelar as 
múltiplas facetas dos processos educativos; 2. ser o melhor meio para compreender a articulação entre teoria e prática; 3. ser um espaço em que há regulação coletiva permanente (NÓVOA, 1997). Embora existam estes elementos nas fontes, é incorreto se supor que nas páginas do periódico está a "história verdadeira" sobre o campo educacional. As revistas pedagógicas são também instituições que participam da estruturação do próprio campo pedagógico, neste sentido, embora as notícias, os artigos, e as polêmicas ajudem o historiador da educação a compor um painel vivo e revelador de personagens, com informações próximas ao fato, ao acontecimento ou ao debate então recente, estes elementos não definem a totalidade do fenômeno por si só. Articular as particularidades que os periódicos permitem alcançar, sem perder de vista a economia política da época e a dinâmica própria das relações culturais que permearam a produção do periódico, parecenos ser um dos desafios ao historiador que se proponha a realizar este tipo de pesquisa (FERNANDES, 2008).

Vale assinalar que pesquisas em História da Educação não precisam lançar mão, exclusivamente, de periódicos que tenham como temática a educação e/ou a pedagogia. Esta concepção poderia ser classificada como simplista, uma vez que mesmo periódicos que não tratam diretamente de questões atinentes à educação, podem se revelar fontes ricas. Jornais e revistas que se ocupem de notícias gerais podem, perfeitamente, ser fontes para pesquisas em História da Educação, na medida em que os debates relativos à educação costumam encontrar nesta mídia um caminho para atingir amplos setores da população. Nestes termos, um periódico pode, inclusive, adquirir um caráter pedagógico, contribuindo para a profusão de um ideário educacional ou de uma perspectiva acerca do que deve ser a educação e sua organização. (MAGALDI, 2008).

$\mathrm{O}$ fato dos reformadores da educação na década de 1930 terem eleito a imprensa periódica como instrumento para a ampla divulgação de suas ideias, como no "Manifesto dos Pioneiros da Educação" em 1932, é modelar para a compreensão de como a imprensa em geral pode se legitimar como fonte para pesquisas em História da Educação. O Manifesto foi estrategicamente publicado em um sábado, 19 de março, concomitantemente em jornais do Rio de Janeiro, São Paulo, Rio Grande do Sul, Paraná, Minas Gerais, São Paulo, Bahia e Pernambuco (SAVIANI, 2008). Com isto, os pioneiros esperavam amplificar o alcance de suas ideias alcançando um impacto social importante. Neste contexto, também vale mencionar a revista católica "A Ordem", publicada desde 1921, que, embora não se trate de uma revista especializada em assuntos pedagógicos, também foi um importante instrumento de divulgação de ideias relativas à educação. Especialmente no contexto do debate com os renovadores da educação, na década de 1930, foi frequentemente defensora dos interesses católicos no campo educacional brasileiro. Este exemplo, também evidencia como, a imprensa periódica em geral, pode ser uma fonte valiosa para pesquisas em História da Educação.

Como um exemplo de pesquisa em História da Educação que lança mão da imprensa periódica geral como fonte, de maneira bastante rigorosa metodologicamente, pode-se citar o livro "Império em Debate: imprensa e educação no Brasil oitocentista" publicado pela Editora da Universidade Estadual de Maringá em 2010. Organizada por Celina Midori Murasse Mizuta, Luciano Mendes de Faria Filho e Marcília Rosa Periotto, esta obra é composta por nove textos que discutem a ação educativa de diversos jornais brasileiros do século XIX. O livro é rico, especialmente, por permitir que a história da educação brasileira nos oitocentos seja recontada a partir de novos parâmetros interpretativos possibilitados pelas fontes adotadas. Na apresentação do livro os organizadores escrevem o seguinte a respeito das fontes utilizadas: 


\begin{abstract}
Alguns dos jornais estudados se notabilizaram por realizar a defesa da educação, pleiteando a fundação de escolas que viessem a combater o alto grau de ignorância da população brasileira, fato que se comprometia as iniciativas em prol de um desenvolvimento social maior e melhorado. Outros, por sua vez, marcaram presença no interior dos debates políticos disseminando ideias e ideais que, se presumia, seriam absorvidos pela população [...] (MIZUTA; FARIA FILHO; PERIOTTO, 2010, p. 11).
\end{abstract}

Como exemplo de trabalho que faz um caminho diferente e se ocupa exclusivamente da imprensa pedagógica, temos o livro "Educação em Revista: a imprensa periódica e a história da educação", organizado pelas professoras Denice Barbara Catani e Maria Helena Camara Bastos e publicado em 1997. Nele são apresentados nove textos que tratam de diferentes temáticas relativas a revistas pedagógicas do século XIX e XX no Brasil, na França e no Portugal (CATANI; BASTOS, 1997). A sistematização de informações sobre os periódicos especializados em educação estudados pelos autores, fornece um material valioso aos pesquisadores que desejam familiarizar-se com este tipo de fonte e com possíveis estratégias para sua abordagem.

\title{
Considerações finais
}

Por definição as fontes históricas são produções humanas e, sejam elas produzidas com propósito de registro ou não, só adquirem sentido mediante a intencionalidade assumida pelo historiador em sua pesquisa. Embora o fato histórico esteja no passado, sua avaliação e problematização são feitas a partir do tempo presente, portanto, são influenciadas pelos problemas aos quais o investigador empenha-se em dar respostas. $\mathrm{Ou}$ seja, são balizadas pelas demandas históricas de uma circunstância específica. A utilização da imprensa periódica em geral como fonte para a escrita da história da educação, mostrase pertinente mesmo quando a temática não é tratada de modo explícito na publicação, uma vez que é possível investigar os aspectos formativos presentes nos textos. Sob esta perspectiva, o conteúdo dos periódicos deve ser entendido como portador de ideias capazes de direcionar a formação dos homens em um sentido amplo.

Ao fazerem circular informações sobre o trabalho pedagógico, sobre a prática docente e seu aperfeiçoamento, sobre o ensino das disciplinas, sobre a organização do sistema de ensino, sobre as reivindicações da categoria profissional, entre outros, os periódicos compõe uma espécie de microcosmo que, tomado como fonte para pesquisa, proporciona ao pesquisador informações ricas sobre o campo educacional. Ao considerar este microcosmo o historiador da educação reúne maiores condições para fazer o recorte de sua pesquisa, definindo com precisão de qual temática e/ou aspecto se ocupará em seu trabalho. Neste sentido, avaliar este microcosmo e encontrar os elementos que compõe e determinam um fenômeno, sem perder-se nos debates acerca das particularidades culturais, parece-nos um dos desafios mais atuais para os historiadores das diferentes áreas.

\section{Referências}

ARNAUT DE TOLEDO, C. A.; GIMENEZ, J. C. Educação e pesquisa: fontes e documentos. In: CASIMIRO, A. P. B. S.; LOMBARDI, J. C.; MAGALHÃES, L. D. R. (Orgs.). A Pesquisa e a Preservação de Fontes para a Educação, Cultura e Memória. Campinas. Alínea, 2009. p. 109-125.

BACELAR, C. Fontes Documentais. Uso e mau uso dos arquivos. In: PINSKY, C. B. (Org.). Fontes Históricas. São Paulo: Contexto, 2006. p. 21-79. 
BASTOS, M. H. C.; MOGARRO, M. J. Manuais de história da educação em Portugal e Brasil (segunda metade do século XIX - primeira metade do século XX). In: ARAÚJO, M. M. (Org.). História(s) Comparadas(s) da Educação. Brasília: Liber Livros, 2009. p. 241283.

BURKE, P. A Revolução Francesa da Historiografia: a escola do Annales (1929-1989).

2. ed. São Paulo: UNESP, 1992.

CAPELATO, M. H.; PRADO, M. L. O bravo matutino. Imprensa e ideologia no jornal O Estado de São Paulo. São Paulo: Alfa Omega, 1980.

CASTANHO, S. Teoria da Históra e História da Educação: por uma história cultural não culturalista. Campinas: Autores Associados, 2010.

CATANI, D. B.; BASTOS, M. H. (Orgs.). Educação em Revista: a imprensa periódica e a História da Educação. São Paulo: Escrituras, 1997.

COSTA, C. J. Fontes jesuíticas e a educação brasileira. In: COSTA, C. J.; PEREIRA MELO, J. J.; FABIANO, L. H. (Orgs.). Fontes e métodos em história da educação. Dourados: UFGD, 2010. p. 193-214.

FERNANDES, A. L. C. O impresso e a circulação de saberes pedagógicos. In:

MAGALDI, A. M. B. M.; XAVIER, L. N. (Orgs.). Impressos e História da Educação: usos e destinos. Rio de Janeiro: 7 Letras, 2008. p. 15-29.

FUNARI, P. P. Fontes Arqueológicas. O historiador e a cultura material. In: PINSKY, C. B. (Org.). Fontes Históricas. São Paulo: Contexto, 2006. p. 81-110.

GRAMSCI, A. Cadernos do Cárcere. 4. ed. Rio de Janeiro: Civilização Brasileira, 2006. v. 2.

LUCA, T. R. História dos, nos e por meio dos periódicos. In: PINSKY, C. B. (Org.).

Fontes Históricas. São Paulo: Contexto, 2006. p. 111-153.

MAGALDI, A. M. B. M.; XAVIER, L. N. Apresentação. In: . (Orgs.). Impressos e História da Educação: usos e destinos. Rio de Janeiro: 7 Letras, 2008. p. 9-14.

MELO, J. J. P. Fontes e Métodos: sua importância na descoberta das heranças educacionais. In: COSTA, C. J.; PEREIRA MELO, J. J.; FABIANO, L. H. (Orgs.). Fontes e métodos em história da educação. Dourados: UFGD, 2010. p. 13-34.

MIZUTA, C. M. M.; FARIA FILHO, L. M.; PERIOTTO, M. R. Império em Debate: imprensa e educação no Brasil oitocentista. Maringá: EDUEM, 2010.

MONARCHA, C. História da Educação Brasileira: atos inaugurais. Horizontes, Bragança Paulista, v. 14, p. 35-44, 1996.

NÓVOA, A. A Imprensa de Educação e Ensino. In: CATANI, D. B.; BASTOS, M. H. Educação em Revista: a imprensa periódica e a História da Educação. São Paulo: Escrituras, 1997. p. 11-31.

PINSKY, C. B. Apresentação. In: (Org.). Fontes Históricas. São Paulo: Contexto, 2006. p. 7-8.

SAVIANI, D. História das ideias pedagógicas no Brasil. 2. ed. Campinas: Autores Associados, 2008.

SAVIANI, D. O debate teórico e metodológico no campo da história e sua importância para a pesquisa educacional. In: SAVIANI, D.; LOMBARDI, J. C.; SANFELICE, J. L. 
(Orgs.). História e História da Educação: o debate teórico-metodológico atual. 3. ed. Campinas: Autores Associados, 2006. p. 7-15.

SAVIANI, D. Breves considerações sobre fontes para a história da educação. Revista HISTEDBR On-line, Campinas, n. especial, p. 28-35, ago. 2006 b.

SAVIANI, D. História e História da Educação na Formação do Educador. In: SCOCUGLIA, A. C.; PINHEIRO, A. C. F. (Orgs.). Educação \& História no Brasil Contemporâneo. João Pessoa: UFPB, 2003. p. 21-36.

SAVIANI, D. A Pós-Graduação em Educação no Brasil: trajetória, situação atual e perspectivas. Revista Diálogo Educacional, v. 1, n. 1, p. 1-19, jan./jun. 2000.

SILVA, C. M. N.; NASCIMENTO, C. V.; ZICA, M. C. Imprensa e educação na segunda metade dos oitocentos. In: MIZUTA, C. M. M.; FARIA FILHO, L. M.; PERIOTTO, M. R. Império em Debate: imprensa e educação no Brasil oitocentista. Maringá: EDUEM, 2010. p. 223-251.

VIDAL, D.; FARIA FILHO, L. História da educação no Brasil: a constituição histórica do campo (1880-1970). Revista Brasileira de História, São Paulo, v. 23, n. 45, p. 37-70, jul. 2003.

Notas

\footnotetext{
${ }^{1}$ Professor Doutor do Departamento de Fundamentos da Educação e do Programa de Pós-Graduação em Educação da Universidade Estadual de Maringá.

${ }^{2}$ Mestre em Educação e aluno de doutorado do Programa de Pós-Graduação em Educação da Universidade Estadual de Maringá.

${ }^{3}$ Em um interessante estudo sobre manuais de História da Educação - no Brasil e no Portugal da segunda metade do século XIX e primeira metade do século XX - Maria Helena Camara Bastos e Maria Joao Mogarro indicam que no Brasil os manuais tinham, fundamentalmente, as seguintes características: visão eurocêntrica; perspectiva cronológica dotada de uma lógica descritiva e/ou interpretativa das ideias; visão de sociedade evolucionista; conteúdo que privilegiava a organização escolar e ideias pedagógicas - com ênfase em eventos, autores e datas importantes (BASTOS; MOGARRO, 2009).

${ }^{4}$ ANPEd - Associação Nacional de Pós-Graduação e Pesquisa em Educação. HISTEDBR - Grupo de Estudos e Pesquisas História, Sociedade e Educação no Brasil.
}

Recebido em maio/2012

Aprovado em novembro/2012 